\begin{abstract}
Purpose: This study explores how children's developing ability to effectively regulate their emotions influences their consumer behavior.

Design/methodology/approach: Working with 80 children and one of their parents, this study used direct observations of child behavior in a task where they needed to regulate their emotions and a survey of parents about their child's emotional development and consumer behavior. The research used quantitative methods to test whether children's emotion regulation predicted parent reported consumer behavior (e.g., purchase requests, parent-child purchase related conflict) via multiple regression analyses.

Findings: After controlling for children's age and linguistic competence, the study found that children’s ability to control positively valenced emotions predicted consumer behavior. Specifically, children who had more difficulty suppressing joy/happiness were more likely to ask their parents for consumer goods and were more likely to argue with parents about these purchases.
\end{abstract}

Practical implications: Content analyses of commercials targeting children have shown that many of the persuasive appeals used by advertisers are emotionally charged and often feature marketing characters that children find affectively pleasing. These findings suggest that these types of marketing appeals may overwhelm younger children which can lead to conflict with parents. Consequently, marketers and policy makers may want to re-examine the use of such tactics with younger consumers.

Originality/value: While the potential link between children’s emotional development and consumer behavior has been suggested in theoretical work, this is the first known study to empirically test this theorized relationship. 
YOUNG CONSUMERS AND AFFECTIVE DEVELOPMENT

Keywords: children, emotion regulation, affective development, cognitive development, consumer behavior

Paper type: Research paper 
YOUNG CONSUMERS AND AFFECTIVE DEVELOPMENT

\section{Emotion Regulation and Young Children's Consumer Behavior}

It is likely every parent's shopping nightmare- the supermarket tantrum. This nightmare starts with a visit to the grocery store with a young child. Initially there are no signs of trouble as both parent and child cruise through the produce section and then the meat/fish section.

However, things take a decided turn when heading down the cereal aisle: the enticing characters on the boxes, the promise of free toys contained within, and the sugar rush that will commence when the product is consumed, call out to the child. At first, the child politely asks if the parent could please purchase her favorite cereal. The parent calmly responds to the child's request by stating that he will not buy a cereal that has sugar listed as one of the primary ingredients. In response, the child's tone becomes a bit more desperate and resolute as she asks again for the cereal. The parent, knowing that he must also be firm, stands his ground and puts the 'healthy' cereal in the shopping cart. At this point, the parent has crossed the grocery store Rubicon and this is when his real nightmare commences, the child wails over her request being ignored and the parent feels his skin crawl while simultaneously worrying that every shopper is thinking the worst about his parenting skills.

To be clear, this is an over-hyped description of a supermarket tantrum, but it is an example that has some ring of truth to it. As Atkin (1978) found in his study of supermarket interactions, arguments between parents and children are quite common and can lead to considerable anxiety for parents. The current study tests whether children's affective development plays a role in influencing these types of parent-child interactions with a specific focus on purchase requests and subsequent purchase conflict with parents. Of particular interest is the role that children's emotion regulation (i.e., their ability to control both positive and 
YOUNG CONSUMERS AND AFFECTIVE DEVELOPMENT

negative emotional responses) plays and whether its development influences children's consumer behavior.

\section{Emotion Regulation}

Emotion regulation is defined as 'the behaviors, skills and strategies, whether conscious or unconscious, automatic or effortful, that serve to modulate, inhibit and enhance emotional experiences and expressions’ (Calkins \& Hill 2007). This can include either subduing or amplifying both negatively and positively valenced emotions. Examples of emotion regulation include stopping oneself from expressing a profane hand gesture while driving, maintaining a somber face when something unexpectedly humorous occurs during a solemn occasion, displaying a guilty demeanor for an infraction that does not actually make you feel guilty, and feigning a look of joy when you receive a gift that you actually do not like. Yet, emotion regulation is not an ephemeral happening. The control and modulation of emotional responses can best be described as a process with continuous feedback, as one situation that requires emotion regulation leads to a different situation which also requires the regulation of emotion.

The study of emotion regulation as a unique research area is a somewhat recent occurrence (Gross 2014). Initial work was done on the subject in the mid-1980s (see Saarni 1984), but it was not until the early 1990s that emotion regulation was thought of as its own particular construct with scholars working to identify how it developed or what actually constituted emotion regulation. However, by working within this conceptual framework, researchers have been able to piece together some compelling discoveries related to both children and adults. In particular, children who are able to regulate emotion effectively enjoy more social and academic success, as these children are more popular, show more social competence and are more sympathetic to the plight of others (Denham et al. 2003; Duckworth \& 
YOUNG CONSUMERS AND AFFECTIVE DEVELOPMENT

Carlson 2013). Most importantly, however, researchers in this area have begun to systematically re-entangle (rather than disentangle) the relationship between emotion and cognition (Damasio 2000).

Emotion Regulation and Development

The development of emotion regulation can be understood as a gradual transfer from mostly external regulation at infancy to predominantly internal regulation of emotions in young children (Calkins 1994; Dodge \& Garber 1991). At the very beginning of life, children rely exclusively on their parents and other caregivers, to soothe and regulate arousal (Kopp 1989; Tronick 1989). For example, if an infant falls down or has a toy taken away, it is typically the caregiver's responsibility to act as the calming agent and not the child itself, as the child is unable to enact internal emotional controls. As children move through infancy and toddler-hood; however, they undergo a number of important neurophysiological changes, which aid in moving the primary responsibility for emotional regulation away from caregivers and onto the child. However, even as children develop the ability to self-regulate emotions on their own, parental involvement still plays a vitally important role, as parent attempts to emotionally socialize their child affects the child's regulatory abilities (Feldman 2015).

The ability to control emotions without the help of others begins in the early preschool years and do not finish maturing until late childhood or even adolescence (Diamond 2002; Munakata et al. 2012). This process is helped along by key changes in the child's brain. As children grow older, their prefrontal cortex (PFC) is maturing and this section of the brain is believed to be responsible for helping children control cognition and emotion (Bunge \& Zelazo 2006; Liu et al. 2009; McRea et al. 2012; Zelazo \& Cunningham 2007). Located in the forebrain, the PFC is the part of the brain chiefly responsible for the regulation of behavior and 


\section{YOUNG CONSUMERS AND AFFECTIVE DEVELOPMENT}

for complex rule use (Bunge \& Zelazo 2006; Luciana \& Nelson 1998). With a less mature PFC, children are not as competent at executing a number of behaviors including; carrying out goal directed behavior, regulating attention, considering others’ belief states, controlling affect, and accessing working memory (Davidson et al. 2000; Liu et al. 2009; Zelazo 2015). Moreover, as studies with adults have shown, those who have significant impairment of the PFC may initially present as normal but, when taxed or stressed, actually exhibit multiple deficits in normal functioning including an inability to control emotional impulses and an inability to plan or focus on long range tasks (Beauregard et al. 2001).

The period where PFC development is most rapid is between the preschool years (i.e., between 3 and 4 years of age) and middle childhood (i.e., between 9 and 11 years of age: Luciana \& Nelson 1998; Welsh et al. 1991). It is during the early to middle elementary school years that children begin to deal with an entirely new set of problems, and that is how to manage both positive and negative emotions in a socially appropriate manner.

\section{Controlling Emotions}

In regards to the control of emotions in positive situations, cognitive and affective development strongly influences the way children react to emotional situations. For example, in the Secret Keeping task (Carlson \& Wang 2007), children are tested on how long they can refrain from revealing exciting news to another person when they have been asked to keep this news secret. Specifically, children are left alone in an observation room where a fish seemingly begins talking to the child. After establishing some rapport with the child, the 'fish' begs the child to not disclose his secret to the researchers, children with better emotion regulation skills are more likely to not only refrain from revealing the secret but can also better control the excitement of finding out that the fish can talk. 


\section{YOUNG CONSUMERS AND AFFECTIVE DEVELOPMENT}

In the negative situations, one task that researchers use comes from the disappointing gift task (Hudson \& Jacques 2014), wherein researchers tell a child that they are going to receive a nice gift. Instead, the researcher gives the child a gift they would likely not want (e.g., a baby rattle, a broken toy). After opening the gift, researchers code the child's reaction and look for indicators that the child either does not like the gift (i.e. negative comments, frowning, shoulder shrugging) or that the child is unable to make a socially appropriate gesture showing gratitude for the gift (e.g., smiling, thanking the gift giver). Children who are less skilled at regulating their emotions will openly show disdain for the gift that they have received. Conversely, as children's emotional skills improve, they will hide their dislike of the gift and as children get better at managing emotions, they may even be able to thank the gift-giver for the gift or display expressions indicating that they are happy with the gift.

In both the secret keeping and disappointing gift task, the child’s ability to regulate their emotional reactions is closely tied to their ability to control cognitions and to not let these emotional situations overwhelm them, as children who succeed at these tasks are those children who are able to ‘override’ their initial emotional reactions (Carlson \& Wang 2007; Hudson \& Jacques 2014; Simonds et al. 2007). Young children are unable to complete these tasks successfully, while older children are able to perform significantly better. As Simonds and her colleagues (2007) found in their test of children's ability to cope with disappointing gifts, the children who were able to enact an appropriate emotional response to receiving the gift (e.g., smiling and saying 'thank you' for the gift) were the oldest children in the sample (10 years old). The youngest children are unable to complete these tasks, while the older children perform significantly better. Even after controlling for age and verbal ability, there is a significant link between emotion regulation and cognitive control (Carlson \& Wang 2007). 
YOUNG CONSUMERS AND AFFECTIVE DEVELOPMENT

\section{Emotion Regulation in Consumer Settings}

Considering the difficulties children face when learning to control their emotions, it is crucially important to understand how advertising appeals are structured for children. As previous content analyses have shown, commercials targeted to children use more emotional appeals than advertisements that target adults (Wicks et al. 2009). Moreover, children’s advertisements frequently include affectively pleasing characters that may likely generate feelings of connection to the brand or character (Kunkel et al. 2009). These factors, combined with children's developing ability to control their emotions, should influence their consumer behavior.

Similarly, Rozendaal and colleagues have recently theorized that children's inability to consistently control their emotional reactions leaves them more vulnerable to persuasive messages as they are unable to critically assess the nature of the message (Rozendaal et al. 2011). These researchers argue that children with less ability to regulate emotions would be less likely to enact a 'stop and think' responses thereby having their affective responses control reactions to persuasive messages. The current study hypothesizes the same relationship with regard to consumer behavior (i.e., purchase requests and purchase related conflict). Specifically, children who are less able to control their emotional reactions should be more likely to ask their parents to purchase consumer goods:

H1a. After controlling for child age and language fluency, children who have more difficulty regulating emotions (as measured by parents) will make more purchase requests.

H1b. After controlling for child age and language fluency, children who have more difficulty coping with positive emotions (as measured by the parents) will make more purchase requests. 
YOUNG CONSUMERS AND AFFECTIVE DEVELOPMENT

H2a. After controlling for child age and language fluency, children who have more difficulty controlling positively valenced emotions, as observed via direct assessment, will make more purchase requests.

H2b. After controlling for child age and language fluency, children who have difficulty controlling negatively valenced emotions, as observed via direct assessment, will make more purchase requests.

Similarly it follows that children's ability to regulate emotion is a key determinant in whether these same children can appropriately cope with purchase request denials on the part of their parents and will engage in more conflict with parents over denials (see Buijzen \& Valkenburg 2003):

H3a. After controlling for age and language fluency, children who have more difficulty regulating emotions will engage in more purchase conflict with parents over purchase request denials.

H3b. After controlling for age and language fluency, children who have difficulty coping with positive emotions will engage in more purchase conflict with parents over purchase request denials.

H4a. After controlling for age and language fluency, children who have more difficulty controlling negative emotions, as observed via direct assessment, will engage in more parent-child conflict with parents over purchase request denials.

H4b. After controlling for age and language fluency, children who have more difficulty controlling positive emotions, as observed via direct assessment, will engage in more parent-child conflict with parents over purchase request denials. 


\section{Methods}

\section{Participants}

The study was conducted in camps and after-school centers in the suburbs of a large Northeastern city. Seventy-nine children participated in this study. Of the sample, there were slightly more girls $(\mathrm{N}=40,50.6 \%)$ than boys $(\mathrm{N}=39,49.4 \%)$. Participating children ranged in age from 6 to 9 years of age $(M=7.7, S D=0.88)$. Of those responding to the question of child race $(n=77$ parents), $81.8 \%$ of the children were identified as Anglo-American $(n=63)$ followed by $11.7 \%$ of the children identified as multi-racial $(n=9)$, with the remaining children identified as either African American ( $\mathrm{n}=2)$ or East Asian/Asian-American ( $\mathrm{n}=3)$.

Because the emotion regulation tasks required videotaping children, parents were given the opportunity to opt out of having their child recorded. Seven parents indicated that they did not want their child recorded. Consequently, for the child observed emotion regulation tests, there were 72 total participants.

\section{Procedures}

The present study was part of a larger study exploring children’s cognitive development and consumer behavior. The study received approval from the Institutional Review Board at the WITHHELD. The study included two observations/interviews with children, parents were asked to fill out a survey regarding their child's development, media exposure, consumer behavior, and family/child demographics. Children received small toys for their participation and parents received monetary compensation for filling out the survey (\$10).

\section{Measures}

\section{Child Measures}


YOUNG CONSUMERS AND AFFECTIVE DEVELOPMENT

Emotion Regulation. The child observation of emotion regulation was based on the disappointing gift task originally employed by Saarni (1984) and has since been widely used to assess children’s emotion regulation capabilities (see Carlson \& Wang 2007; Garner \& Power 1996; Kieras et al. 2005; McDowell et al. 2000; McDowell \& Parke 2005) as children’s emotional reactions to the gifts have been shown to be consistently predictive of their emotion regulation skills. In the current study, the procedures were based on those used by Simonds et al, (2007). At the beginning of the first session, children were presented with an array of both age/gender appropriate and age inappropriate toys. The assessor showed each toy to the target child and explained what each toy did. The child was then asked if they could tell the assessor which two toys were the child's favorite and which one was their least favorite. The toys presented to each child were: a wind-up motorcycle, a sticky lizard, a stamp, a super popper (a piece of rubber that makes a popping sound), a putty animal, noise putty, notepad, and baby rattle. The child was given approximately two minutes to play with the toys and ask questions about each of the toys. The assessor then recorded the child's favorite, second favorite, and least favorite gifts.

At some point during the first assessment, the assessor placed the toy selected as the child's top choice in a gift bag and placed tissue over the toy. At the very end of the assessment, the assessor presented the child the gift bag and told the child that they could open the bag in the assessment room (children were told that they had to open it during the assessment because there were not enough gift bags for all of the children). While the child opened the gift bag, the assessor maintained complete silence and pretended to make notes of the data collection for approximately 15 seconds after the toy was given to the child. The child's reactions to the toy were videotaped. 
YOUNG CONSUMERS AND AFFECTIVE DEVELOPMENT

At the end of the second data collection session, the child received another gift from the assessor and the same procedures noted with the first assessment were observed. However, this time the child 'mistakenly' received the toy that they reportedly liked least of all. After the 15 second waiting period was over, the assessor told the child that there must have been a mistake and exchanged the undesirable toy with the child's second favorite toy. The child's reaction was recorded on videotape. Eight children did not have permission from their parents to videotape and one child's observation during the desired gift presentation was obscured and was unable to be coded.

Displays of emotion were coded by two raters for the time immediately following children's discovery of their particular gift (i.e., when it became apparent that the child knew what gift they had received). Coding of children's responses lasted either for the first 15 seconds after the child had seen the gift or when the assessor first talked with the child after receiving the gift (whichever was shorter). After learning the code, the trained coders independently coded $20 \%$ of the sample to determine reliability (Cohen's kappa for each measure are noted below). After coder reliability was established, one coder coded the remaining videos. Children were scored along the following dimensions: the type of smile evidenced by the child (no smile, grin or forced smile, and broad smile), whether the child said 'thank you' after receiving the gift, whether the child said something positive about the gift, whether the child said something negative about the gift, and how much the child appeared to like the gift.

Broad smiles were defined as corners of the mouth clearly turned upward with the mouth opened while grin or forced smiles were defined as times when the corners of the mouth were turned upward but the child's mouth was not open $(0=$ no smile, $1=$ grin or forced smile; $2=$ full smile; first session $\mathrm{M}=1.38, \mathrm{SD}=0.76$; second session $\mathrm{M}=0.81, \mathrm{SD}=0.74 ; \kappa=.84)$. $\mathrm{A}$ 
YOUNG CONSUMERS AND AFFECTIVE DEVELOPMENT

child was reported to have said thank you if the child explicitly expressed thanks for the gift by saying 'thank you' or 'thanks' $(0=$ no, $1=$ yes; first session $M=0.36, S D=0.48$; second session $\mathrm{M}=0.19 \mathrm{SD}=0.40 ; \kappa=1.00)$. A statement was scored as positive if the child declared that they liked/loved the toy or made a favorable comment about the toy (e.g., 'wow, this is really neat', 'this is just what I wanted'; $0=$ no, $1=$ yes; first session $\mathrm{M}=0.32, \mathrm{SD}=0.47$; second session $\mathrm{M}$ $=0.08, \mathrm{SD}=0.28 ; \kappa=.75)$. Statements that indicated dislike/hatred for the toy, sadness about receiving a toy or unfavorable comments about the toy (e.g., 'I don't want this') were scored as negative $(0=$ no, 1 = yes; first session $M=0.04, S D=0.20$; second session $M=0.23, \mathrm{SD}=$ 0.43; $\kappa=1.00)$. Statements that indicated both like and dislike for the toy (e.g., 'I don’t really like this toy, but thank you for giving it to me') were scored as both positive and negative. Lastly, children's liking of the gift was coded along a 5-point scale $(1=$ disliked very much; $5=$ liked very much). For a child to receive a score of 1 , they had to display extreme emotional negativity towards the gift (e.g., frowning, refusing to accept the gift) and/or say something very negative about the gift. Conversely, for a child to receive a score of 5, they had to display obvious elation over receiving the gift and/or provide statements suggesting that they liked the gift (first session $\mathrm{M}=3.87, \mathrm{SD}=0.79$; second session $\mathrm{M}=2.47, \mathrm{SD}=1.19 ; \kappa=.91$ ).

Children's reactions to the varying gifts went as expected for each of the variables. Specifically, children were more likely to respond positively to the desired gift and more likely to respond negatively to the non-desired gift. With regard to smiling, when children received the desired gift they were significantly more likely to smile compared to when they received the disappointing gift, $\mathrm{t}(70)=4.97, \mathrm{p}<.001$. Children were significantly more likely to say thank you when receiving the desired gift than when given the disappointing gift, $\mathrm{t}(71)=2.98, \mathrm{p}<.01$. They were also more likely to say something positive about receiving the desired gift, $\mathrm{t}(71)=$ 
YOUNG CONSUMERS AND AFFECTIVE DEVELOPMENT

3.52, $\mathrm{p}<.01$, and were more likely to say something negative about the disappointing gift, $\mathrm{t}(71)$ $=-3.58, \mathrm{p}<.01$. Lastly, children appeared to like receiving the desired gift more than the disappointing gift, $\mathrm{t}(70)=8.82, \mathrm{p}<.001$.

For the purposes of hypothesis testing, the two separate measures of children's overall observed response to the desired gift and undesired gift were used. These measures were chosen because they were both correlated with other aspects of gift reception. With regard to children children's observed liking of the desired gift, their reactions were significantly correlated with each of the specific observations and all in the expected direction: how much the child smiled $(\mathrm{r}(71)=.72, \mathrm{p}<.001)$, whether the child said thank you after receiving the gift $(\mathrm{r}(71)=.23, \mathrm{p}=$ $.05)$ whether the child made a positive comment about the gift $(\mathrm{r}(71)=.53, \mathrm{p}<.001)$, and whether the child made a negative comment about the gift $(r(71)=-.23, p=.05)$. The observed relationships between how much the child responded to the undesired gift and the specific observations were also significant and in the expected direction: how much the child smiled $(r(72)=.49, \mathrm{p}<.001)$, whether the child said thank you $(\mathrm{r}(72)=.25, \mathrm{p}<.05)$, whether the child made a positive comment $(\mathrm{r}(72)=.60, \mathrm{p}<.001)$, and whether the child made a negative comment about the gift $(\mathrm{r}(72)=-.56, \mathrm{p}<.001)$.

Test of Verbal Ability

Because children's general intellectual ability could potentially act as a confound. A measure of children vocabulary was included in the study. Children’s verbal ability was tested with one of the subtests from the Woodcock-Muñoz Language Survey-Revised (WMLS-R; Woodcock et al. 2001). The specific subtest used was the Picture Vocabulary Test. Children were presented with a page of pictures and were asked to provide the word that matched the 
YOUNG CONSUMERS AND AFFECTIVE DEVELOPMENT

picture. Children were given a score of 0 for incorrect identification and a score of 1 for correct identification, with results summed to create a total score $(\mathrm{M}=34.80$, $\mathrm{SD}=3.68)$.

\section{Parent Measures}

\section{Emotion Regulation}

The child's emotion regulation skills were assessed with two separate parent report measures. These two measures assess separate aspects of emotion regulation the first measure (the Emotion Regulation Checklist) looks at both positive and negative emotion regulation while the second measure (Positively Valenced Emotion Regulation) only explores how children handle very positive emotions. For the purposes of hypothesis testing, both scales were used. Emotion Regulation Checklist (ERC). This 23-item parent report measure has 2-sub scales and was designed to assess the child's emotional lability and emotion regulation skills, the emotion regulation sub-scale was the only scale used in the current study (Shields \& Cicchetti 1997). All items were measured on a 4-point scale (0- 'Never’; 3- 'Almost always’).

The emotional regulation scale consists of 8-items and asked about the child's ability to control emotional impulses. The scale included questions such as 'My child is a cheerful child', 'My child responds positively when other children approach my child', and 'My child responds positively when adults approach him/her in a friendly or neutral way'. The scale demonstrated adequate internal consistency $(\alpha=.70)$ and was transformed using a squared transformation due to issues of normality, $\mathrm{M}=371.84, \mathrm{SD}=105.68$ with higher scores indicating better emotional control.

Positive Coping. This was a researcher developed parent-report measure that was designed to investigate how well the child does coping with positive emotions and situations that the child might find overwhelming (e.g., surprises, very good news). It was a 5-item measure with 
YOUNG CONSUMERS AND AFFECTIVE DEVELOPMENT

questions such as 'When your child experiences a very positive emotion, how often do they scream or shout for joy?', 'When your child experiences a very positive emotion, how often do they become hard for you to control?' All questions were answered with a 5-point scale $(0=$ Never to $4=$ Always $)$. The scale initially demonstrated poor reliability $(\alpha=.67)$, but was improved by removing one item $(\alpha=.73$, 'Does child scream or shout for joy'; $M=3.48$, SD = 2.32).

Purchase Requests \& Purchase Conflict. This set of questions was adapted from Buijzen \& Valkenburg (2003). While the original measure only assessed the purchasing of 4-items, the measure used for the current study increased the number of products that were asked about. Specifically, this measure was a 10-item parent-report measure of children's purchase requests and purchase conflict. The products included were: toys, media products (e.g., DVDs), candy, video games, clothes, snack food, fast-food restaurants, non fast-food restaurants, movies, and amusement parks.

The measure of purchase requests asked parents to indicate how often the child asked them to buy the selected goods with the results summed across product types $(0=$ 'Never'; $3=$ 'Always'). The scale demonstrated adequate reliability $(\alpha=.71 ; \mathrm{M}=15.42, \mathrm{SD}=3.82)$. Parents were then presented with a follow up question which asked how intense arguments with their child was over the purchase of these selected consumer goods ( $0=$ 'Never'; $3=$ 'Always'). Responses were summed across product types and the scale demonstrated very good reliability $(\alpha=.88 ; \mathrm{M}=10.46, \mathrm{SD}=5.20)$. 
YOUNG CONSUMERS AND AFFECTIVE DEVELOPMENT

Analysis Strategy

Ordinary least square regressions were used for all hypothesis testing (see Table 1 for all zero order correlations for the variables of interest). For all of these tests, child age, and linguistic competence served as control variables. Significance levels at $\mathrm{p}<.05$ were considered significant while $\mathrm{p}<.10$ was considered marginally significant. All analyses were conducted with SPSS 19.0.

\section{[Insert Table 1 Here]}

\section{Results}

\section{Emotion Regulation and Purchase Requests}

The first test of children's emotion regulation skills and their influence on purchase requests employed parent report of emotion regulation skills and included age and language fluency as control variables using a hierarchical regression analysis (hypothesis 1a). The model was not significant, $F(3,75)=1.61, p=.20$, as neither child age $(\beta=-.03, p=0.85)$ nor language fluency $(\beta=-.23, p=0.11$ ) were linked with parent-reported purchase requests. More importantly, parent report of children’s emotion regulation was not linked to parent reported purchase requests $(\beta=-.05, \mathrm{p}=0.63)$. Thus, hypothesis 1a was not supported.

The second test of children's emotion regulation skills tested whether parent reported positive coping skills of their children predicted purchase requests with the same covariates noted above (see Table 2). The model was significant, $F(3,75)=5.48, \mathrm{p}<.01, \mathrm{R}^{2}=.18$, child age was not correlated with purchase requests $(\beta=-.004, p=0.97)$ but linguistic competence was marginally associated with requests $(\beta=-.23, \mathrm{p}<.09)$. More importantly results show support for hypothesis $1 \mathrm{~b}$ as parent reported child coping skills were correlated with purchase requests ( $\beta$ 
YOUNG CONSUMERS AND AFFECTIVE DEVELOPMENT

$=.35, \mathrm{p}=.001)$. Specifically, children who had more difficulty with controlling their reactions to positive situations asked their parents for more consumer goods.

[Insert Table 2 Here]

Hypotheses 2a and 2b predicted that children's observed reaction to receiving gifts would be associated with parent reported purchase requests. This test included child age and child linguistic ability as control variables, the model was not significant $\left(F(4,65)=1.17, \mathrm{p}=.33, \mathrm{R}^{2}=\right.$ .07). Neither of the control variables explained a significant amount of variance and the observed emotion regulation variables were not significant predictors of parent reported purchase requests (reception of desired gift: $\beta=.09, p=0.46$; reception of non-desired gift: $\beta=-.06, p=0.65$ ). Emotion Regulation and Purchase Conflict

Hypothesis 3a predicted that children with more well developed emotion regulation capabilities would engage in fewer conflicts with parents over purchase request denials. The first test of emotion regulation used the parent-report of children's emotion regulation and included both child age and child linguistic competence as control variables. The regression was not significant, $F(3,75)=0.52, p=.67$ as neither child age $(\beta=.01, p=0.97)$ or child linguistic competence $(\beta=.01, \mathrm{p}=0.94)$ were significant predictors of purchase conflict. More importantly, the addition of parent reported emotion regulation was not significant $(\beta=-.14, \mathrm{p}=$ 0.23).

Hypothesis 3b predicted that parent reported positive child coping would be associated with parent reported purchase conflict and used the same covariates noted above. The model was not significant, $F(3,75)=0.72, p=.55, R^{2}=.03$, with neither age $(\beta=.01, p=0.95)$ or linguistic competence $(\beta=.03, \mathrm{p}=0.85)$ predicting conflict. In addition, parent reported child coping was not significantly correlated with purchase conflict $(\beta=.16, \mathrm{p}=0.15)$ although there was a trend 
YOUNG CONSUMERS AND AFFECTIVE DEVELOPMENT

suggesting that children who had more difficulty coping with positively valenced emotions fought with their parents more over consumer decisions.

The final tests of emotion regulation and purchase conflict used the child observations from when they received both the desired and the non-desired gift (hypothesis 4a and 4b). Similar to the test for parent reported emotion regulation and purchase conflict, this test used child age and child linguistic competence as control variables (which, as noted above were not significant predictors of purchase conflict). The complete regression model was not significant $\left(\mathrm{F}(4,65)=1.18, \mathrm{p}=.38, \mathrm{R}^{2}=.07\right)$. However, the addition of the observed child reactions did indeed reveal that children's observed reaction to the desired gift significantly predicted parent reported purchase conflict $(\beta=.26, \mathrm{p}<0.05)$ as children who exhibited more joy with receiving the desired gift were more likely to argue about purchases with their parents (see Table 3). Children's reaction to the non-desired gift was not significantly related to parent reported purchase conflict $(\beta=-.01, \mathrm{p}=0.92)$.

\section{[Insert Table 3 Here]}

\section{Discussion}

While previous scholars have suggested that emotion regulation should influence children’s susceptibility to persuasive messages and consumer behavior (Rozendaal et al. 2011), this is the first known study to test the relationship between emotion regulation and consumer behavior. As Rozendaal and colleagues have theorized, emotion regulation should play an important role in shaping how children respond to persuasive messages, as the strongly affective nature of the messages override a child's ability to consider the message. In the current study, the relationship between emotion regulation and child consumer behavior was tested; while the results are not uniform, they do suggest that children's ability to control emotions plays a role in 
shaping children's consumer behavior, particularly children's ability to rein in excitement. First, the study did find that children's observed reaction to the gift task predicted parent-child consumer conflict and that this relationship held after accounting for child age and linguistic ability. Specifically, at the end of the first assessment, children were given the toy that they had earlier stated was their favorite and were then recorded while receiving the gift. The results revealed that children who expressed more positive reactions to this wanted gift (as opposed to the undesired gift) were also significantly more likely to argue with parents about denied purchase requests. This finding suggests that children who are more likely to become emotionally engaged when encountering positively valenced stimuli are more likely to struggle with purchase refusals from their caretakers. However, this is not the only potential explanation which could explain this finding. For example, it may be that children who really like toys were more likely to get excited to receive the gift and are more likely to argue with their parents about toy (or other purchases). More research is needed to determine if this is an emotion regulation issue or an issue related to children's material connection to consumer goods.

Second, the parent measure looking at how their children were able to cope with situations that require their child to deal with exciting emotional situations (e.g., receiving a surprise or good news) significantly predicted parent reported purchase requests and there was a trend suggesting a link between child coping and parent reported purchase conflict. What the current study found was that children who had a more difficult time coping with exciting situations were more likely to ask their parents to purchase consumer goods and may be more likely to argue with their parents over purchase refusals.

This set of findings point to an interesting link between children's ability to cope with exciting situations and consumer behavior. The observational measure and the parent report 
measure both suggest that children who are less able to deal with excitement are more likely to ask their parents to purchase consumer goods and argue with them over purchases. Moreover, these results hold even after accounting for the role that age and children's linguistic competence play in shaping consumer behavior and emotion regulation.

Contrary to expectations, children's negative reactions to the gifts were not connected to consumer behavior. Specifically, children's reactions to the undesired gift in the second assessment (the undesired gift that was the one they liked the least when they were presented during the first assessment) did not predict purchase requests or parent-child conflict during purchase denials. The fact that these relationships did not exist with children's negative reactions to the undesired gift is somewhat surprising as children's negative behavioral and emotional reactions to parent's consumer decisions are frequently discussed in the literature (Atkin 1978; Henry \& Borzekowski 2011). For example, Atkin’s early work on parent-child consumer interactions only focused on how children's negative reactions led to parent and child disputes in the supermarket as children who expressed obvious disappointment with parent decisions escalated these disagreements. However, in this study, children's inability to cope with disappointing situations did not appear to matter. The underlying reason for this lack of a finding may be connected to the age of the children in this study. The earlier research exploring children's tantrum behaviors and consumer interactions typically studied children in their pre-K to kindergarten years.

This difference in the age of the sample studied may explain why reactions to the positive stimuli were predictive of consumer behavior in this study and negative reactions were not. Expressing extreme negative reactions to disappointing information is typically more accepted with younger children while older children are expected to be better able to control their 
YOUNG CONSUMERS AND AFFECTIVE DEVELOPMENT

reactions to emotional situations as they reach their elementary school years. Conversely, the ability to adequately control emotional reactions to positive experiences is still something that children are still learning while getting over-stimulated by these positive experiences are not as harshly judged by peers and caregivers. For example, in a longitudinal study conducted by Murphy and colleagues (1999), the researchers tracked children’s displays of both positive and negative emotions from the preschool years to middle school. Reports from parents indicated a precipitous drop in the negative emotions displayed by children between the preschool and early elementary years yet after entering school, there was little change in children's displays of negative emotion (mean scores for negative emotionality: ages $4-6=4.01$, ages $6-8=2.08$, ages 8-10 $=1.97$, ages 10-12 $=1.75$ ). The researchers did not find, however, a similar change in displays of positive emotions as these remained consistently higher over the school years. In other words, a child in elementary school who behaves a little too 'hyper' or over-stimulated when excited is less likely to encounter condemnation from peers or caregivers than a child who exhibits tantrum behaviors when things do not go well. On a related note, it would be interesting to further explore the role that impulsivity in children plays here. Research with adults has shown that those adults who struggle more to control impulses are more likely to act on these impulses in similar situations (Shiv \& Fedorikhin, 1999).

With this difference in how separate emotional reactions are accepted by others in mind, the children participating in the current study may have been past the typical level of emotional development where the behaviors associated with extreme negative reactions are commonplace and more accepted. Perhaps if this study investigated children at preschool or kindergarten age (i.e., four to five year olds), the link between children's negative reactions to the undesired gift 


\section{YOUNG CONSUMERS AND AFFECTIVE DEVELOPMENT}

and parent-child purchase disagreements would have been stronger while children's reaction to the desired gift would have not been predictive of parent-child disagreement.

There were a couple of surprising results from the other tests of emotion regulation and consumer behavior. It is unclear why there were no observed relationships between the measure of emotion regulation and children's consumer behavior. The parent measure used for this study, (Emotion Regulation Checklist (ERC); Shields \& Cicchetti, 1997), has been regularly used to test children's emotional development and is recognized as a valid measure of emotion regulation in children.

One potential reason for the lack of a significant finding is that the ERC assesses a separate aspect of emotion regulation. The researchers who developed the measure primarily work in the field of developmental psychopathology and the instrument has been used to assess children whose difficulties to control emotions have negatively impacted their engagement with peers, family members, and other caregivers. As such, the measure used for the present study may not have been able to make the necessary differentiations in children’s emotional development to clearly demarcate children who lagged in emotion regulation versus those who were able to capably control their emotions. However, the descriptive statistics from the measure used do not indicate that there were noticeable restrictions in variance which would have limited the ability to find effects.

Secondly, this parent measure of emotion regulation was not significantly correlated with the observational measures of emotion regulation (see Table 1). However, when looking at the three primary measures of emotion regulation, the measure of children's positive coping behaviors was correlated with both the Emotion Regulation Checklist and the observational measure (although these were only marginally correlated) indicating that there was some overlap 
YOUNG CONSUMERS AND AFFECTIVE DEVELOPMENT

between the measures indicating that these measures were uncovering something important as it relates to emotional development and regulation.

Implications

As noted above, there was not uniform support for the findings related to emotion regulation and consumer behavior. However, one potential implication of the current study is the further integration of the study of development within the field of children and media. Of particular concern is the role that emotion and its regulation play in children's responses to persuasive messages. While researchers have begun to show that emotional appeals are frequently used in children’s advertisements (e.g., Wicks et al., 2009) and have expressed concerns about their use (Harris 2014), we still do not have a strong research base to work off of when it comes to understanding how children respond to these types of appeals.

On a more practical/policy note, a topic of considerable interest among children and advertising scholars is how we might protect children from intrusive advertisements (e.g., Livingstone \& Helsper 2006). The results of the current study offer some initial evidence that targeting children's emotions may be one way to help children bolster their defenses against persuasive messages. For example, it may help to employ consumer based interventions which target children's emotional reactions to commercial messages. Rather than trying to teach children about the purpose of advertisements and then hoping that this knowledge will cue children's skepticism about the appeal, these interventions attempt to generate negative attitudes about advertising which then leads to fewer purchase requests. Research by Buijzen (2007), suggests that these types of interventions are successful in reducing purchase requests and are actually more successful than interventions that seek to improve advertising knowledge. 


\section{YOUNG CONSUMERS AND AFFECTIVE DEVELOPMENT}

Specifically, Buijzen had research assistants say negative things about advertisements while they were shown to children and then tested whether these comments changed their behavior relative to children who did not receive the intervention. She found that children in the intervention were less likely to like the products and were less likely to request the products. Future research should determine whether the developmental variables under investigation in the current study may play a role in explaining this relationship. For example, it may be that children who are less able to regulate emotion are more likely to have these comments influence their later assessments as they are less able to control how these emotionally framed comments influence their thoughts.

\section{Limitations}

One issue that hampered this study was its small sample size. With approximately 80 children and their parents participating, this study’s ability to detect significant effects was limited (although the sample size for this study is larger than what was obtained for similar studies exploring these constructs; e.g., $\mathrm{N}=$ 53- Carlson \& Wang 2007, $\mathrm{N}=$ 47- Simonds et al. 2007). Unfortunately, this researcher encountered a number of obstacles when trying to recruit both childcare programs/schools and parents to participate. Schools that had been contacted to participate in the study typically declined because data collection sessions were viewed as too disruptive to the school day while afterschool programs usually declined because of space and resource limitations. In addition, when permission was eventually secured from a day camp/afterschool program, there was a low response rate from parents even after numerous and varied attempts to recruit participants.

The second limitation was the inability of researchers to code precise facial features with the child participants, as had been done in previous research (e.g., Carlson \& Wang 2007). The 
YOUNG CONSUMERS AND AFFECTIVE DEVELOPMENT

resolution of the video cameras did not allow for as precise of coding as was desired. Future research should use recording technology that makes capturing these subtle changes in affect easier.

Finally, the focus of the current study was on how children's affective development via cognitive maturation influences consumer behavior. However, there are certainly other elements of children's development that should be considered in future studies that this study did not address. For example, while children’s cognitive maturation does drive specific aspects of emotion regulation (Ochsner et al. 2012), parental socialization also plays a significant role in shaping children's emotional development as parents' emotional expressiveness is linked to their own child's expressiveness (Halberstadt et al. 1993). In fact, it is likely the case that children's growing ability to control their emotions is the result of a dynamic interplay between cognitive development and caregiver influence (Feldman 2015). Future research should specifically investigate how parents’ attempts to emotionally socialize their children affects consumer behavior with a particular focus on parents’ own self-regulation skills.

\section{Conclusion}

In a recent essay by Harris (2014), the author noted that research on children and advertising should focus more on the role that emotion plays in affecting children's reactions to persuasive messages. The findings of this study provide initial evidence that understanding children's development of emotion regulation skills may help us understand their consumer behavior and compares well with recent theorizing on development and persuasion by Rozendaal and colleagues. However, given that this study is one of the first investigations of children's affective development and consumer behavior, more research is definitely needed to fully understand how emotion regulation affects consumer development. 


\section{References}

Atkin, C.K., 1978. Observation of parent-child interaction in supermarket decision-making. Journal of Marketing, 42(4), pp.41-45.

Beauregard, M., Lévesque, J. \& Bourgouin, P., 2001. Neural correlates of conscious selfregulation of emotion. Journal of Neuroscience, 21(18), pp.6993-7000.

Buijzen, M., 2007. Reducing Children’s Susceptibility to Commercials: Mechanisms of Factual and Evaluative Advertising Interventions. Media Psychology, 9(2), pp.411-430. Available at: http://www.tandfonline.com/doi/abs/10.1080/15213260701291361 [Accessed February 21, 2014].

Buijzen, M. \& Valkenburg, P.M., 2003. The Unintended Effects of Television Advertising: A Parent-Child Survey. Communication Research, 30(5), pp.483-503. Available at: http://crx.sagepub.com/cgi/doi/10.1177/0093650203256361.

Bunge, S.A. \& Zelazo, P.D., 2006. A Brain-Based Account of the Development of Rule Use in Childhood. Current Directions in Psychological Science, 15(3), pp.118-121. Available at: http://cdp.sagepub.com/content/15/3/118.abstract [Accessed November 1, 2015].

Calkins, S.D., 1994. Origins and outcomes of individual differences in emotion regulation. Monographs of the Society for Research in Child Development, 59(2-3), pp.53-72. Available at: http://doi.wiley.com/10.1111/j.1540-5834.1994.tb01277.x [Accessed August 27, 2015].

Calkins, S.D. \& Hill, A., 2007. The emergence of emotion regulation: Biological and behavioral transactions in early development. In J. Gross, ed. Handbook of Emotion Regulation. New York, NY: Guilford Press, pp. 229-248.

Carlson, S.M. \& Wang, T.S., 2007. Inhibitory control and emotion regulation in preschool 
YOUNG CONSUMERS AND AFFECTIVE DEVELOPMENT

children. Cognitive Development, 22(4), pp.489-510.

Damasio, A.R., 2000. Descartes' error: Emotion, reason, and the human brain 6th ed., New York, NY: Quill.

Davidson, R.J., Putnam, K.M. \& Larson, C.L., 2000. Dysfunction in the Neural Circuitry of Emotion Regulation--A Possible Prelude to Violence. Science, 289(5479), pp.591-594. Available at: http://www.sciencemag.org/content/289/5479/591.abstract [Accessed October $1,2015]$.

Denham, S.A., Blair, K.A., DeMulder, E., Levitas, J., Sawyer, K., Auerbach-Major, S. and Queenan, P., 2003. Preschool emotional competence: Pathway to social competence?. Child Development, 74(1), pp.238-256.

Diamond, A., 2002. Normal development of prefrontal cortex from birth to young adulthood: Cognitive functions, anatomy, and biochemistry. In D. T. Stuss \& R. T. Knight, eds. Principles of frontal lobe function. London, UK: Oxford University Press, pp. 466-503.

Dodge, K.A. \& Garber, J., 1991. Domains of emotion regulation. In J. Garber \& K. A. Dodge, eds. The Development of Emotion Regulation and Dysregulation. Cambridge, UK: Cambridge University Press, pp. 159-181.

Duckworth, A. L., \& Carlson, S. M., 2013. Self-regulation and school success. In B.W. Sokol, F.M.E. Grouzet, \& U. Müller, eds. Self-regulation and autonomy: Social and developmental dimensions of human conduct. New York, NY: Cambridge University Press, pp. 208-230.

Feldman, R., 2015. Mutual influences between child emotion regulation and parent-child reciprocity support development across the first 10 years of life: Implications for developmental psychopathology. Development and Psychopathology, 27(4), pp.1007-1023.

Garner, P.W. \& Power, T.G., 1996. Preschoolers’ emotional control in the disappointment 
YOUNG CONSUMERS AND AFFECTIVE DEVELOPMENT

paradigm and its relation to temperament, emotional knowledge, and family expressiveness. Child development, 67(4), pp.1406-1419. Available at:

http://www.ncbi.nlm.nih.gov/pubmed/8890491 [Accessed November 1, 2015].

Gross, J.J., 2007. Handbook of emotion regulation J. J. Gross, ed., New York, NY: Guilford Press.

Halberstadt, A.G., Fox, N.A. and Jones, N.A., 1993. Do expressive mothers have expressive children? The role of socialization in children's affect expression. Social Development, 2(1), pp.48-65.

Harris, J.L., 2014. Demonstrating the harmful effects of food advertising to children and adolescents. In A. B. Jordan \& D. Romer, eds. Media and the well-being of children and adolescents. New York, NY: Oxford University Press, pp. 44-51.

Henry, H.K.M. \& Borzekowski, D.L.G., 2011. The Nag Factor: A mixed-methodology study in the US of young children's requests for advertised products. Journal of Children and Media, 5(3), pp.298-317. Available at: http://dx.doi.org/10.1080/17482798.2011.584380 [Accessed May 5, 2014].

Hudson, A. and Jacques, S., 2014. Put on a happy face! Inhibitory control and socioemotional knowledge predict emotion regulation in 5-to 7-year-olds. Journal of Experimental Child Psychology, 123, pp.36-52.

Kieras, J.E., Tobin, R.M., Graziano, W.G. and Rothbart, M.K., 2005. You can't always get what you want effortful control and children's responses to undesirable gifts. Psychological Science, 16(5), pp.391-396.

Kopp, C.B., 1989. Regulation of distress and negative emotions: A developmental view. Developmental Psychology, 25, pp.343-354. 
YOUNG CONSUMERS AND AFFECTIVE DEVELOPMENT

Kunkel, D., McKinley, C. \& Wright, P., 2009. The impact of industry self-regulation on the nutritional quality of foods advertised on television to children, Available at: http://www.childrennow.org/index.php/learn/reports_and_research/article/576 [Accessed May 14, 2014].

Liu, D., Sabbagh, M.A., Gehring, W.J. and Wellman, H.M., 2009. Neural correlates of children’s theory of mind development. Child Development, 80(2), pp.318-326.

Livingstone, S. \& Helsper, E.J., 2006. Does Advertising Literacy Mediate the Effects of Advertising on Children? A Critical Examination of Two Linked Research Literatures in Relation to Obesity and Food Choice. Journal of Communication, 56(3), pp.560-584. Available at: http://doi.wiley.com/10.1111/j.1460-2466.2006.00301.x [Accessed May 24, 2014].

Luciana, M. \& Nelson, C.A., 1998. The functional emergence of prefrontally-guided working memory systems in four- to eight-year-old children. Neuropsychologia, 36(3), pp.273-293. Available at: http://www.ncbi.nlm.nih.gov/pubmed/9622192 [Accessed November 1, 2015].

McDowell, D., O’Neil, R. \& Parke, R., 2000. Display Rule Application in a Disappointing Situation and Children’s Emotional Reactivity: Relations With Social Competence. MerrillPalmer Quarterly, 46(2), pp.306-324. Available at: http://digitalcommons.wayne.edu/mpq/vol46/iss2/7 [Accessed November 1, 2015].

McDowell, D.J. \& Parke, R.D., 2005. Parental Control and Affect as Predictors of Children’s Display Rule Use and Social Competence with Peers. Social Development, 14(3), pp.440457. Available at: http://doi.wiley.com/10.1111/j.1467-9507.2005.00310.x [Accessed November 1, 2015].

McRae, K., Gross, J.J., Weber, J., Robertson, E.R., Sokol-Hessner, P., Ray, R.D., Gabrieli, J.D. 


\section{YOUNG CONSUMERS AND AFFECTIVE DEVELOPMENT}

and Ochsner, K.N., 2012. The development of emotion regulation: an fMRI study of cognitive reappraisal in children, adolescents and young adults. Social Cognitive and Affective Neuroscience, 7(1), pp.11-22.

Munakata, Y., Snyder, H.R. and Chatham, C.H., 2012. Developing cognitive control: Three key transitions. Current Directions in Psychological Science, 21(2), pp.71-77.

Murphy, B.C., Eisenberg, N., Fabes, R.A., Shepard, S. and Guthrie, I.K., 1999. Consistency and change in children's emotionality and regulation: A longitudinal study. Merrill-Palmer Quarterly, 45(3), pp.413-444.

Ochsner, K.N., Silvers, J.A. and Buhle, J.T., 2012. Functional imaging studies of emotion regulation: a synthetic review and evolving model of the cognitive control of emotion. Annals of the New York Academy of Sciences, 1251(1), pp.E1-E24.

Rozendaal, E., Lapierre, M.A., Van Reijmersdal, E.A. and Buijzen, M., 2011. Reconsidering advertising literacy as a defense against advertising effects. Media Psychology, 14(4), pp.333-354.

Saarni, C., 1984. An observational study of children’s attempts to monitor their expressive behavior. Child Development, 55(4), pp.1504-1513.

Shields, A. \& Cicchetti, D., 1997. Emotion regulation among school-age children: The development and validation of a new criterion Q-sort scale. Developmental psychology, 33(6), pp.906-916. Available at: http://www.ncbi.nlm.nih.gov/pubmed/9383613 [Accessed August 11, 2015].

Shiv, B. and Fedorikhin, A., 1999. Heart and mind in conflict: The interplay of affect and cognition in consumer decision making. Journal of Consumer Research, 26(3), pp.278-292.

Simonds, J., Kieras, J.E., Rueda, M.R. and Rothbart, M.K., 2007. Effortful control, executive 
YOUNG CONSUMERS AND AFFECTIVE DEVELOPMENT

attention, and emotional regulation in 7-10-year-old children. Cognitive Development, 22(4), pp.474-488.

Tronick, E.Z., 1989. Emotions and emotional communication in infants. American Psychologist, 44(2), pp.112-119. Available at: http://europepmc.org/abstract/med/2653124 [Accessed November 1, 2015].

Welsh, M.C., Pennington, B.F. \& Groisser, D.B., 1991. A normative-developmental study of executive function: A window on prefrontal function in children. Developmental Neuropsychology, 7(2), pp.131-149. Available at:

http://www.tandfonline.com/doi/abs/10.1080/87565649109540483 [Accessed November 1, 2015].

Wicks, J.L., Warren, R., Fosu, I. and Wicks, R.H., 2009. Dual-modality disclaimers, emotional appeals, and production techniques in food advertising airing during programs rated for children. Journal of Advertising, 38(4), pp.93-105.

Woodcock, R. W., Munoz-Sandoval, A. F., Ruef, M., \& Alvarado, C. G., 2001. Woodcock Munoz-Sandoval Language Survey- Revised, Itsaca, IL: Riverside Publishing.

Zelazo, P.D., 2015. Executive function: Reflection, iterative reprocessing, complexity, and the developing brain. Developmental Review, 38, pp.55-68.

Zelazo, P.D. \& Cunningham, W., 2007. Executive function: Mechanisms underlying emotion regulation. In J. Gross, ed. Handbook of Emotion Regulation. New York, NY: Guilford Press, pp. 135-158. 